ERRATA

\title{
Erratum to: Treatment Considerations for Recurrent MRSA Bacteremia Leading to Cholecystitis
}

\author{
Jenna Martin, $B S^{7}$, Daniella Miller, $B A^{7}$, and Geraldine E. Ménard, $M D^{2}$ \\ ${ }^{1}$ Medical student, Tulane University School of Medicine, New Orleans, LA, USA; ${ }^{2}$ Associate Chief for Inpatient Medicine, Associate Professor of \\ Internal Medicine, Section of General Internal Medicine, Tulane University School of Medicine, New Orleans, LA, USA.
}

$\mathrm{J}$ Gen Intern Med 26(7):821

DOI: $10.1007 / \mathrm{s} 11606-011-1677-\mathrm{x}$

(c) Society of General Internal Medicine 2011

\section{Erratum to: J Gen Intern Med \\ DOI: $10.1007 / \mathbf{s} 11606-011-1634-8$}

On page 2 of the original publication, the caption for Figure 1 reads: "Figure 1. CT scan of the abdomen showing two large stones (thick arrow) in the gallbladder (thin arrow) and evidence of thickening of the gallbladder wall." The revised version below clarifies that each arrow points to a stone, rather than that the thin arrow points to the gallbladder itself. The revised caption should read: "Figure 1. CT scan of the abdomen showing two large stones (thick arrow, thin arrow) in the gallbladder and evidence of thickening of the gallbladder wall."

Corresponding Author: Geraldine E. Ménard, MD; Associate Chief for Inpatient Medicine, Associate Professor of Internal Medicine, Section of General Internal Medicine, Tulane University School of Medicine, 1430 Tulane Avenue, SL-16, New Orleans, LA 70112, USA (e-mail: gmenard@tulane.edu).

The online version of the original article can be found at http://dx.doi.org/10.1007/s11606-011-1634-8.

Published online March 8, 2011 